\title{
Sri Guru Nanak Dev Ji self-help group who started with nothing: An inspiration
}

Shivani Rana, Avneet Kaur and Amarjeet Kaur

Received: 31.01.2019; Accepted: 25.05.2019

See end of the paper for authors' affiliations

Shivani Rana

Krishi Vigyan Kendra,

Samrala, Ludhiana (Punjab) India
KEY WORDS: Self-help group, Started with nothing

- HOW TO CITE THIS PAPER : Rana, Shivani, Kaur, Avneet and Kaur, Amarjeet (2019). Sri Guru Nanak Dev Ji self-help group who started with nothing : An inspiration. Asian J. Home Sci., 14 (1) : 226-229, DOI: 10.15740/HAS/AJHS/14.1/226-229. Copyright@ 2019: Hind Agri-Horticultural Society. 